\title{
Disclosure of Maternal HIV Status to Children: To Tell or Not To Tell ... That Is the Question
}

Tanya L. Tompkins

Linfield College

Follow this and additional works at: https://digitalcommons.linfield.edu/psycfac_pubs

Part of the Child Psychology Commons, and the Maternal and Child Health Commons

\section{DigitalCommons@Linfield Citation}

Tompkins, Tanya L., "Disclosure of Maternal HIV Status to Children: To Tell or Not To Tell ... That Is the Question" (2007). Faculty Publications. Accepted Version. Submission 3.

https://digitalcommons.linfield.edu/psycfac_pubs/3

This Accepted Version is protected by copyright and/or related rights. It is brought to you for free via open access, courtesy of DigitalCommons@Linfield, with permission from the rights-holder(s). Your use of this Accepted Version must comply with the Terms of Use for material posted in DigitalCommons@Linfield, or with other stated terms (such as a Creative Commons license) indicated in the record and/or on the work itself. For more information, or if you have questions about permitted uses, please contact digitalcommons@linfield.edu. 
ORIGINAL PAPER

Disclosure of Maternal HIV Status to Children: To Tell or Not To Tell... That is the Question

Tanya L. Tompkins

Running head: Disclosure of Maternal HIV Status to Children

T.L. Tompkins

Department of Psychology, Linfield College, 900 SE Baker Street, A570, McMinnville, OR 97128

e-mail: tatompki@linfield.edu 


\begin{abstract}
HIV-infected mothers face the challenging decision of whether to disclose their serostatus to their children. From the perspective of both mother and child, we explored the process of disclosure, providing descriptive information and examining the relationships among disclosure, demographic variables, and child adjustment. Participants were 23 mothers and one of their noninfected children (9 to 16 years of age). Sixty-one percent of mothers disclosed. Consistent with previous research, disclosure was not related to child functioning. However, children sworn to secrecy demonstrated lower social competence and more externalizing problems. Differential disclosure, which occurred in one-third of the families, was associated with higher levels of depressive and anxiety symptoms. Finally, knowing more than mothers had themselves disclosed was related to child maladjustment across multiple domains. Clinical implications and the need for future research are considered.
\end{abstract}

Keywords: Disclosure • Secrecy • HIV/AIDS • Child adjustment • Maternal illness 
As rates of HIV infection and AIDS steadily increase in women of child-bearing age, the HIV/AIDS epidemic has taken on a new face, evolving into a disease of women, families, and children. A disproportionate number (77\%) of women infected with HIV/AIDS are AfricanAmerican or Hispanic (Centers for Disease Control and Prevention [CDC], 2002) and many are of low-income status. Most HIV-infected women are within their reproductive years (CDC, 2002) and many are unmarried and have multiple young children in their care (Dorsey et al., 1999). Although it has been proposed that AIDS will have claimed enough lives to orphan an estimated 70,000 to 125,000 children in the U.S. alone (Joint United Nations Programme on HIV/AIDS, 2000), recent treatment advances suggest that a growing number of noninfected children will develop to maturity within families affected by HIV/AIDS. Our understanding of how families adjust and cope with HIV/AIDS is in its infancy. Needed is more information about the ways in which seropositive parents can effectively manage the physical and psychosocial effects of their illness to minimize the risk conferred on their children.

Living with a stigmatizing and chronic terminal illness, seropositive mothers must grapple with the difficult decision of whether and when to inform their children about their diagnosis, weighing the potential benefits and costs associated with disclosure (e.g., Antle et al., 2001). Various rates of disclosure of parental HIV/AIDS to children have been reported, ranging from 0\% (Esposito et al., 1999) to 74\% (Armistead et al., 1997, 2001; Bauman et al., Camacho et al., 2002; Forsyth et al., 1996; Lee \& Rotheram-Borus, 2002; Murphy et al., 2001; Murphy, Marelich et al., 2002; Nagler et al., 1995; Niebuhr et al., 1994; Nostlinger et al, 2004; Ostrom et al., 2006; Pilowsky et al., 1999; Rotheram-Borus et al., 1997; Schrimshaw \& Siegel, 2002; Shaffer et al., 2001; Sowell et al., 1997; Tompkins et al., 1999; Wiener et al., 1998), and likely 
depend on such factors as child age, disease progression, quality of the parent-child relationship, and general cultural influences on disclosure- and child-related beliefs. Although parents commonly cite protection from distress as a major reason for withholding illness-related information from children, clinical observation indicates that children typically have some sense that something is wrong anyway (Melvin, 1996).

On the other hand, children who are informed about their mother's HIV status may also be at risk for maladjustment given the "web of silence" that may accompany disclosure (Murphy, Roberts et al., 2002). Differential disclosure within families is not uncommon as parents choose to tell certain children (e.g., eldest child), but not others. For example, Ostrom et al. (2006) found that $20 \%$ of the participating mothers had told "some" of their children. Over the course of their 5-year longitudinal study, Rotheram-Borus et al. (1997) found that approximately 20$30 \%$ of participating parents disclosed to only some of their children, creating a context of family secrecy (Lee \& Rotheram-Borus, 2002). Given that such communication patterns are consistently associated with unhealthy family adjustment in other areas of research and the fact that researchers tend to adopt a dyadic approach in exploring HIV/AIDS disclosure within families, little is known about differential disclosure.

Extant research has yielded mixed results in terms of correlates and outcomes of disclosure. Many studies support a developmental progression of disclosure, whereby infected parents are more likely to disclose to older children (Armistead et al., 1997, 2001; Lee \& Rotheram-Borus, 2002; Rotheram-Borus et al., 1997; Schrimshaw \& Siegel, 2002; Shaffer et al., 2001; Tompkins et al., 1999; Wiener et al., 1998). This decision may result from the mothers' perceptions that older children will more likely understand the implications of such news and 
will, perhaps, be better equipped to keep the disclosed diagnosis confidential (e.g., Murphy, Roberts et al., 2002). Additionally, several studies investigating whether disclosure varies with child gender suggest that daughters are more likely to be informed of their parents' serostatus (Armistead et al., 2001; Lee \& Rotheram-Borus, 2002; Shaffer et al., 2001); others, however, have found no effect of child gender on parents' disclosure decisions (Armistead et al., 1997; Rotheram-Borus et al., 1997). In light of these inconsistent findings and broader research suggesting that female children may adopt increased caretaking roles when a parent is ill with cancer (Grant \& Compas, 1995), it is important to evaluate whether gender differences in disclosure rates occur in families affected by HIV/AIDS.

Recent research has also revealed mixed findings as to whether disclosure of parental HIV/AIDS to children varies by ethnicity. Some investigations have failed to find ethnic differences in rates of disclosure (Lee \& Rotheram-Borus, 2002; Murphy et al, 2001; Schrimshaw \& Siegel, 2002), while others have found higher rates among Caucasian families (Armistead et al., 1997; Niebuhr et al., 1993) and/or lower rates among Latina families (Tompkins et al., 1999). Given that previous research examining general disclosure of HIV/AIDS has documented ethnic variation in rates of disclosure (Simoni et al., 1996) and that cultural values may influence the decision to disclose to children in a variety of different ways, it is important to examine whether and how ethnicity may influence disclosure of parental HIV infection to children.

Other sociodemographic variables (e.g., marital status, education, socioeconomic status) have also been investigated in relationship to disclosure. Armistead et al. (2001) found that lowincome mothers were more likely to have disclosed their serostatus to their children relative to 
mothers with greater financial resources, perhaps due to practical limitations (e.g., lack of privacy, no child care) that make concealment of their health status more difficult. Clarifying contextual factors that may impinge on the disclosure process is critical given that such moderating factors may ultimately inform intervention efforts with HIV-affected families. Both recent evidence with HIV-affected parents (Armistead et al., 1997; Bauman et al., 2002; Lee \& Rotheram-Borus, 2002; Schrimshaw \& Siegel, 2002) and research on other parental illnesses (e.g., Jamison \& Walker, 1992) provide support for the view that parents inform their children about their health status when deteriorating health and/or imminent death hastens disclosure. The above consensus is not without exception, however. Results from the Family Health Project (e.g., Armistead et al., 2001; Shaffer et al., 2001) have not revealed a relationship between stage of illness and disclosure. Furthermore, results from studies demonstrating a relationship between illness severity and disclosure highlight the need for refinement in our understanding of this association. For example, Schrimshaw and Siegel (2002) indicate that this relationship is confounded by time such that women in the later stages of illness may have experienced a larger window of opportunity in which to disclose. In fact, Bauman and colleagues (2002) found that the relationship between illness severity and disclosure no longer reached significance once the effects of child age were controlled, thus suggesting that the link to illness severity is more complex than increased symptoms, visibility, and/or impairment.

Of the few studies that have investigated HIV-infected parents' disclosure decisions, many have focused on or included disclosure of seropositive status to children who themselves may be infected (e.g., Lester et al., 2002), focused solely on reasons for non-disclosure (Faithfull, 1997; Moneyham et al., 1996; Murphy et al., 2001), and/or failed to include the child's 
perspective of the disclosure process (Faithfull, 1997; Moneyham et al., 1996; Ostrom et al., 2006; Pilowsky et al., 1999; Schrimshaw \& Siegel, 2002). Several authors have proposed that a multitude of factors may be associated with the decision to disclose including: decreased parental stress associated with keeping the "secret" and hiding health seeking behavior (Armistead \& Forehand, 1995), decreased child stress related to living with an unnamed illness (Murphy et al., 2001; Nagler et al., 1995; Ostrom et al., 2006), increased control over the process of disclosure (Murphy et al., 2003; Ostrom et al., 2006), improved communication to facilitate sharing of accurate information regarding the disease and prevention (Armistead et al., 1999; Schrimshaw \& Siegel, 2002); desire to share the news before severe illness or death ensues (Schrimshaw \& Siegel, 2002); and increased opportunity to involve children in future planning and to prepare for future loss (Armistead et al., 1997; Ostrom et al., 2006; Pilowsky et al., 1999). Extending beyond an examination of correlates and reasons for disclosure, several recent studies have sought to understand the relationship between parental disclosure and children's mental health, yielding mixed results. Some investigations have suggested that disclosure is not predictive of either mother- or child-reported internalizing difficulties once potentially confounding demographic (Armistead et al., 2001; Bauman et al., 2002) and family process (Armistead et al., 1997) variables were controlled. Others (Rotheram-Borus et al., 1997) have revealed heightened and relatively stable (Lee \& Rotheram-Borus, 2002) rates of problem behaviors among adolescents who were informed of their parents' diagnosis. Several studies suggest the importance of considering additional moderating factors, such as time since disclosure (Murphy, Marelich et al., Hoffman, 2002; Schrimshaw \& Siegel, 2002), maternal illness severity (Murphy, Marelich et al., 2002), and informant differences (Shaffer et al., 2001). 
In general, these studies demonstrated lower levels of child maladjustment among children who were informed (Murphy, Marelich et al., 2002), especially when children's self-reports of behaviors were considered (Shaffer et al., 2001) and when child functioning was assessed after a period of initial adjustment (Murphy, Marelich et al., 2002; Schrimshaw \& Siegel, 2002).

Despite the relative paucity of information about disclosure of maternal HIV infection to children and mixed results from recent studies, professionals are frequently consulted regarding the disclosure process. The purpose of this study is threefold. First, we extended previous work by examining rates and correlates of disclosure. Specifically, we expected that disclosure would be related to child age, gender, and ethnicity, such that the highest rates of disclosure would occur in European-American families, and that older children and daughters would be more likely to know their mothers' diagnosis. Other demographic factors (e.g., SES, illness severity) were also explored but given the dearth of related findings specific hypotheses were not advanced. Second, we sought to understand more clearly the process of disclosure and to clarify and further past findings by expanding the definition of disclosure to include mother and child descriptions of the process. To our knowledge, only one prior study has included youths' perspectives of maternal disclosure (Murphy, Roberts, \& Hoffman, 2006). To further elucidate the context surrounding the disclosure process we also aimed to describe and explore issues of secrecy, prior knowledge, and differential disclosure within the family. Finally, we sought to examine if and how disclosure relates to child adjustment. Given past inconsistent findings regarding the association between disclosure and child adjustment, no specific hypotheses were offered. 


\section{Method}

Participants

Twenty-three women living with HIV/AIDS and one of their 9- to 16-year-old noninfected children (14 girls and 9 boys) participated in the current investigation. The oldest child over the age of 9 who was enrolled in a local school was recruited for participation. The families were primarily from ethnic minority (9 African-American, 11 Latina, 3 European-American) and economically disadvantaged backgrounds.

\section{Procedure}

All participants were recruited from the greater Los Angeles area and had previously participated in the UCLA-Drew Women and Family Project (WFP), a comprehensive, longitudinal study investigating psychosocial adjustment, risk behavior, and social contexts in a multi-ethnic sample of HIV-infected and noninfected women (see Wyatt \& Chin, 1999). All participants were given the choice of being assessed at the Fernald Child Study Center at UCLA or their home and were compensated ( $\$ 50$ per family) for their time. For the 18 women who elected to be interviewed at home, it was confirmed the physical environment would be suitable for research purposes. For families who opted to be assessed on campus but did not have transportation or childcare, these services were provided.

All procedures were reviewed and approved by the Institutional Review Board (IRB) at UCLA. Written consent and verbal assent was obtained from mothers and children, respectively, following a thorough description of the study during the first session. As part of the consent for the HIV positive group, data were collected on the nature of disclosure (i.e., what words have and 
have not been used by the mother to communicate about her illness or infection to the child) as a step in eliciting information to be used with the child during the second interview. Standard sample scenarios were reviewed during the consent and first interview to ensure that each mother understood how issues of disclosure would be handled with her child. For instance, it was thoroughly explained that the child interviewer would disclose only that information which the mother had previously reported to the project, unless the child spontaneously discussed more than the mother reported or was aware of, in which case the child interviewer would use words or phrases congruent with the child's reported knowledge of their mother's illness status.

Each child and mother participated in two separate interview sessions, with an average of 8 days between interviews. In addition, teachers were asked to complete (and provided modest compensation) measures assessing children's behavior problems and competence. In order to protect the families' privacy the study was described to teachers as being about stress and coping. A medical chart review was used to obtain basic information about the HIV-positive mothers' illness which allowed for classification of disease status according to CDC HIV-staging procedures.

\section{Measures}

Areas of interest included basic demographic information (e.g., age of mother, age of child, educational attainment, employment information, family structure, etc.), disclosure information, maternal health status, maternal psychosocial functioning, and child psychosocial functioning. 


\section{Disclosure}

Through the use of both open-ended questions and structured ratings, information regarding the process of disclosure (e.g., when child was told, what words were used to inform the child, emotional reaction to the news, whether the child knew something prior to disclosure, additional information the child had beyond what the mother had shared, whether the child was asked to keep the information secret, ratings of satisfaction and regret about telling/knowing, and reasons for feeling good and bad about the telling/knowing) was obtained during the mother's first interview (average of 2 hours duration) and, if children were informed of maternal illness, was also gathered during the child's second interview (average of $13 / 4$ hours duration). All interviews were audiotaped for later transcription and analysis. All ratings were measured on a 4-point scale ranging from 0 (not at all true) to 3 (very true), with higher scores reflecting greater degrees of a given emotion, satisfaction, regret or greater importance of the stated reason for disclosure or non-disclosure. For mothers who had not yet disclosed, information was obtained regarding reasons for nondisclosure, age of the child at the time of anticipated disclosure, and what the predicted circumstances would be at the point of future disclosure (e.g., who would be present, whether she would tell in parts or all at one time, whether there were things she would not tell). Additionally, parallel to the measure used to assess regret and satisfaction with disclosure, nondisclosed mothers were asked to rate the importance of several factors in explaining why it might be good or bad to tell in the future.

Interviewers reviewed the disclosure protocol and provided separate ratings of the mother's and child's view of the child's level of knowledge and understanding of the mother's illness on a 6-point scale (0 - "knows nothing," 1 - "knows a very limited amount," 2 - "knows a 
limited amount," 3 - "knows a fair amount," 4 - "knows a moderate amount," and 5 - "knows everything”), with higher numbers reflecting greater understanding. Interrater reliability was found to be acceptable for all ratings ( $90 \%$ agreement).

\section{Illness Severity and Health Status}

For seropositive mothers, information regarding their health status (e.g., date of diagnosis, most recent CD4 counts, most recent viral load levels, CDC staging status) was obtained through a medical chart review by medical personnel or directly from the WFP. Each HIV participant was placed into one of three severity groups based on information extracted from their medical charts: (1) HIV positive, asymptomatic; (2) HIV positive, symptomatic; (3) AIDS diagnosis.

Perceived severity of maternal illness was assessed via a single item asking mothers and disclosed children to indicate how "bad" their (or their mother's) illness was on a 5-point scale (0 $=$ not bad, $4=$ very $b a d)$. Mother and child perceptions of illness-related stress were obtained in a similar manner with both responding to a single item asking about how upsetting their (or their mother's) illness was for them right now on a 5-point scale ranging from 0 (not at all upsetting) to 4 (very upsetting). Higher scores reflect a greater degree of perceived severity and stress.

\section{Child Psychosocial Functioning}

Three areas of children's psychosocial adjustment were examined: (1) behavior problems (internalizing and externalizing), (2) psychological symptoms (depression and anxiety), and (3) sense of competence (cognitive and social) and self-worth.

To assess behavior problems, mothers completed the Child Behavior Checklist (CBCL; 
Achenbach, 1991a), teachers the Teacher Report Form (TRF; Achenbach \& Edelbrock, 1986; Edelbrock \& Achenbach, 1984), and children the Youth Self Report Form (YSR; Achenbach, 1991b), all widely used instruments that are well-standardized and reliable measures of children's behavior problems. Raw scores on the scales were converted to T-scores based on age and gender norms with higher scores indicating more problematic behavior. Broadband internalizing and externalizing behavior problems were the variables of interest in the study.

Mother and child reports of competence across different domains (scholastic competence, social acceptance, athletic competence, physical appearance, behavioral conduct) and global selfworth were assessed using the Parent's Rating Scale of Child's Actual Competencies (PRS; Harter, 1985) and the Self-Perception Profile for Children (SPPC; Harter, 1985), respectively. Additionally, teacher reports of competence and self-worth were gathered employing a teacher version of the PRS. Each item was scored from 1 to 4 , where a score of 1 indicates low competence or self-worth and a score of 4 indicates high competence or self-worth. After reverse scoring items that presented the less competent option first, items were summed within the various domains with higher scores reflecting greater perceived competence.

\section{Results}

Mothers disclosed diagnostic status to the participating child in $61 \%$ of the families.

Overall, only $22 \%$ of the target children were told nothing about their mother's illness. Of the 14 informed children, $9(64 \%)$ indicated they knew how their mother became infected and $6(43 \%)$ indicated they knew she was ill before she disclosed diagnostic information. Within families, $35 \%$ of mothers living with HIV told none of their dependent children about their diagnosis, 
whereas $44 \%$ told all of their children. The mean number of years between diagnosis and disclosure to the child was years 5.4 years $(S D=4.31)$. The mean number of years between disclosure and the interview was 3.7 years $(S D=2.39)$.

Mothers and children described similar patterns of child emotional responses to the initial disclosure, including being "somewhat" or "very": worried (64\% mothers, $71 \%$ children), sad (72\% mothers and children), shocked (50\% mothers, $72 \%$ children), confused (71\% mothers, $64 \%$ children), and hopeful (50\% mothers, $72 \%$ children). Less prominent were angry (36\% mothers, $29 \%$ children) and relieved (21\% mothers, $29 \%$ children) responses. In describing their children's current emotional response to being informed, mothers indicated that, in comparison to their initial reaction, their children were significantly less worried, $t(13)=-2.26, p<.05$; less confused, $t(13)$ $=-4.18, p<.001$ and more hopeful, $t(13)=2.22, p<.05$ (see Table I). In describing their own current emotional state about knowing of their mothers' diagnosis, children reported that they were significantly less sad, $t(13)=-2.35, p<.05$; less shocked, $t(13)=-5.40, p<.001$ and less confused, $t(13)=-5.14, p<.001$ than they were initially. While mother and child reports of current feelings were generally congruent, children reported higher current rates of worry (67\%) relative to mother $(21 \%)$ reports, $t(13)=2.60, p<.05$ (see Table I).

\section{Insert Table I here}

Mothers reported feeling generally satisfied $(M=3.94, S D=1.35)$ with their decision to disclose to their children, demonstrating relatively low levels of regret $(M=1.65, S D=.86), t(16)$ $=4.75, p<.001$. In explaining this satisfaction, mothers most frequently endorsed, as being somewhat or very important, the following reasons: child able to participate in decisions affecting her/him (100\%), mother feeling less stress (86\%), improved health (71\%), easier to engage in 
health seeking behaviors (64\%), talk with child more now (57\%), and child feeling less stress and worry now (57\%). Although mothers generally reported experiencing little regret, the most frequently cited reasons for feeling badly about disclosure related to concerns about the potential negative impact on the child of disclosure $(50 \%$ child asks and worries about mother's health, $21 \%$ child feels more stress and worries more now). Thus, although mothers attributed both satisfaction and regret to child stress, a greater number seemed to feel that disclosure led to relatively more stress-relief, than stress-induction. In fact, mothers endorsed a significantly greater proportion of overall reasons for feeling satisfied $(M=.58, S D=.24)$, than regretful $(M=$ $.15, S D=.23), t(13)=6.09, p<.001$. Children also endorsed a significantly greater proportion of reasons for feeling "glad" $(M=.52, S D=.21)$, rather than "bad" $(M=.22, S D=.19)$ about knowing their mother's serostatus, $t(13)=5.00, p<.001$. Most salient among children's reasons for feeling good were: being able to better prepare for the future $(93 \%)$, being able to make decisions affecting them in the future $(86 \%)$, reducing mother's stress associated with keeping the "secret" (79\%), bringing them closer to their mother (79\%), being able to talk openly (67\%), and worrying and being less afraid (50\%). Only $21 \%$ endorsed decreased stress associated with pretending they did not know something was wrong when they did and 36\% indicated feeling good about knowing because their fears seemed worse than the situation really was. In terms of feeling "bad" about knowing, children most frequently endorsed worrying about their mother dying (83\%), worrying too much about the future (69\%), finding out things about their mother they wish they never knew (29\%), and worrying peers would find out and not like them (29\%).

Nine mothers indicated that they had not informed their child about their diagnosis. Only one mother reported that she had not thought about telling her child, but all nine indicated they 
would probably (56\%) or definitely (45\%) tell their child when s/he reached the mean age of 15.2 years. Eighty-nine percent indicated they would tell their child "all at once" and half reported that they would disclose alone. One-third of the mothers indicated that there would be certain things they would not tell when they informed their child of their diagnosis (e.g., mode of transmission). Reasons provided in support of non-disclosure generally reflected concerns about: child protection ( $100 \%$ child would worry about mother dying, $56 \%$ child would worry too much about the future, $56 \%$ child might get too scared), stigma (67\% worry child will tell others, $56 \%$ would have to tell child things s/he might not like or understand, $56 \%$ worry others will reject us), and developmental inappropriateness (78\% now is not the right time, $67 \%$ child is too young). The most frequently endorsed reasons to disclose in the future involved the possibility of being able to talk openly with the child (78\%) and the reduced worry that the child might find out the information in another way $(67 \%)$.

Within four of the disclosed families, it was jointly understood that the children should keep the mother's HIV status to themselves. However, in two additional cases the mothers indicated that they had asked their child to "keep the secret," while the children indicated they had not been asked to do so. In four separate cases, children reported that they had been asked to keep their mother's diagnosis secret, while the mothers themselves reported that they had not made such requests for secrecy. In considering those four families who have clear secrecy agreements, no consistent differences regarding child psychosocial adjustment were found. However, in the eight cases where children reported that their mothers had asked them not to divulge information, scores on the internalizing subscale of the TRF were higher for those children sworn to secrecy $(M$ =56), than those who were not $(M=38), t(9)=4.86, p<.01$. In the six cases where mothers 
indicated that they had requested their children to keep the secret, no differences emerged for broadband scores on the TRF, CBCL, or YSR. Interestingly, however, mothers reported higher delinquency scores for those children they had asked to keep the information private $(M=63.5)$, than for those not asked to keep the secret $(M=52), t(12)=2.93, p<.05$.

With respect to demographic factors, children from single-parent, as opposed to dualparent households, were more likely to know of their mothers' diagnostic status (83\% vs. 36\%), $\chi^{2}(1, N=23)=5.32, p<.05$, indicating that those who are partnered or married are less likely to inform their child about their illness. Furthermore, children who had lost a father to AIDS were marginally more likely to be informed of their mothers' health condition $(88 \%)$ relative to children whose fathers were living $(46 \%), \chi^{2}(1, N=23)=3.65, p<.06$. There were no significant differences in disclosure rates for mother's income, educational level, ethnicity, or mother's age.

With regard to child factors, unexpectedly, neither child age nor child gender differed between those who knew and did not know their mother's diagnosis. However, results were in the expected direction with disclosed children $(M=13.1$ years, $S D=2.18)$ being marginally older than those who did not know their mother's diagnosis $(M=11.9$ years, $S D=1.43), t(21)=1.48, p$ $<.15 ; r(23)=.31$ and with girls $(64 \%)$ being more likely to be disclosed to than boys $(56 \%)$.

Among the maternal health-related variables, no significant effect emerged for disclosure and time since diagnosis, $t(21)=1.12, p>.05$, although mothers who had disclosed to their children had generally known about their condition longer $(M=9.2$ years $)$ than those who had not yet told their children $(M=7.6$ years). No significant effect emerged between disclosure and stage of illness, nor for disclosure and CD4 counts, although those who had disclosed their serostatus to their child tended to have lower counts $(M=433.6)$ than those who had not yet 
disclosed $(M=595), t(21)=1.64, p>.05$. A significant effect, however, did emerge for disclosure and mother's self-report of upset associated with her illness, $t(20)=3.83, p<.001$ and children's self-report of perceived seriousness of mother's illness, $t(16)=2.76, p<.05$. Somewhat unexpectedly, more disclosure occurred in families where mothers reported being less upset by their illness and children perceived their mother's illness as being less severe.

In terms of child psychosocial adjustment, no group differences were found for child behavioral/emotional problems. However, there was a trend for those who had not been informed of their mother's HIV infection $(M \mathrm{~s}=62.25$ and 61.13$)$ to receive significantly elevated scores on the attention problems subscale of the CBCL and TRF, respectively, as compared to those who knew about their mother's diagnosis $(M \mathrm{~s}=55.64$ and 55.09), $t(20)=2.23, p=.15$ and $t(17)=$ $3.47, p=.08$. With respect to perceived competence, children in the non-disclosed group were found to have marginally higher levels of self-reported self-worth $(M=3.44, S D=.40)$ than children who knew their mother's diagnosis $(M=3.11, S D=.40), t(21)=1.99, p=.06)$.

Of interest was whether discrepancies in knowledge (either knowing more or less) between child and mother report were related to child psychosocial adjustment. Consistently, children who directly reported more knowledge about their mother's illness than she, herself, reported and children whose mothers indicated they likely knew more than she had disclosed, evidenced higher levels of maladjustment and lower competence. For example, a greater percentage (100\%) of children who reported more knowledge than their mothers had disclosed evidenced clinically significant levels of teacher-reported externalizing problems than children who reported similar $(9 \%)$ or less $(60 \%)$ knowledge, $\chi^{2}(2, N=12)=9.20, p<.01$. Similarly, children who knew more than their mothers reported they knew, evidenced marginally higher 
rates of clinically significant levels of mother-reported internalizing problems (67\%), as compared to children who reported knowing the same $(9 \%)$ or less $(14 \%)$ than their mothers reported they

knew, $\chi^{2}(2, N=12)=5.60, p=.06$. Additionally, children whose mothers assumed their children knew more than they had disclosed demonstrated significantly higher levels of mother-reported internalizing $(M \mathrm{~s}=63.25$ vs. 47.33$)$ and externalizing $(M \mathrm{~s}=68.75$ vs. 50.42$)$ problems, as compared to children whose mothers indicated that their children did not know more than what they, themselves, had disclosed, $t(14)=2.64, p<.05, t(14)=2.50, p<.05$, respectively. In terms of self-perception variables, children who reported knowing more than they had been told about their mother's condition received lower teacher ratings of behavioral competence $(M=1.17, S D=$ $.24)$, in comparison to children who reported similar $(M=3.06, S D=.85)$ or lesser $(M=3.50, S D$ $=.79)$ levels of knowledge, $F(2,14)=5.84, p<.05$.

\section{Discussion}

In grappling with this complex decision, the majority of participating mothers perceived relatively more advantages than costs associated with telling their children about their health status. In explaining positive feelings about the disclosure, both children and mothers most frequently cited increased child involvement and decreased maternal stress. Disclosure regrets, which were few, most frequently concerned fear of increased child stress and worry.

Interviews with mothers who had not yet disclosed suggested that all of these mothers would tell their children in the future. Concerns about child protection, developmental inappropriateness, and stigma were cited by these mothers as reasons for not having told. In considering future disclosure, mothers endorsed open communication and avoidance of 
inadvertent disclosure as reasons for disclosing diagnostic status to children. In light of results suggesting that children's negative emotional reactions decrease over time while hope increases following initial disclosure, such information may prove useful in preparing mothers who are contemplating disclosure to expect a wide range of initial emotional reactions from their children. Additionally, for mothers who are not yet ready to tell their children, it may be comforting to know that others share their concerns and have also made a choice to delay disclosure. Similarly, being able to normalize both mother and child reactions to disclosure may be helpful in assisting individual families cope with the stress associated with disclosure-related decisions. It is important to note that the current examination of emotional reactions to disclosure over time was reliant on retrospective mother and child reports. Further longitudinal research would be able to provide more detailed information about the process of disclosure as it unfolds over time.

The disclosure rates found in the current sample were significantly higher than rates reported by the Family Health Project (e.g., Armistead et al., 2001) and the PACT study (e.g., Murphy et al., 2001), but fairly consistent with rates found in other studies of parental AIDS (Rotheram-Borus et al., 1997), HIV-infected fathers with hemophilia (Armistead et al., 1997), and parental HIV/AIDS (Forsyth et al., 1996; Lee \& Rotheram-Borus, 2002; Schrimshaw \& Siegal, 2002). Although discrepancies among studies may be explained in a number of ways, as suggested by Armistead and colleagues (2001), perhaps the most parsimonious explanation is age. Samples with older children generally evidence higher rates of disclosure.

Unexpectedly, and contrary to past findings that support a developmental hypothesis of disclosure, associations between child age and disclosure failed to reach significance in the current sample. Still, children for whom disclosure had occurred were marginally older than those 
who did not know about their mothers' serostatus, and when considering all children of HIVpositive women, children who knew were significantly older than those who did not. These results are consistent with past research in the area (Armistead et al., 1997, 2001; Rotheram-Borus et al., 1997; Wiener et al., 1998) and with developmental factors endorsed as reasons for non-disclosure. Failing to confirm a hypothesized effect of child gender, daughters were not significantly more likely to have been disclosed to by their HIV-infected mothers. These findings replicate results from studies of parents with AIDS (Rotheram-Borus et al., 1997) and HIV-infected fathers with hemophilia (Armistead et al., 1997), but are opposite those reported for African-American families affected by maternal HIV infection (Armistead et al., 2001) and for mothers among a sample of parents with HIV/AIDS who disclosed more frequently to daughters (Lee \& RotheramBorus, 2002). Additionally, the present results are at odds with research suggesting that adolescent females are more likely than their male counterparts to be involved in family life following maternal illness (Grant \& Compas, 1995). Given the wide variations in sociodemographic characteristics among these samples (e.g., ethnicity, gender of the ill parent, disease status, child age), discrepancies regarding child gender effects are difficult to interpret. Further explanations await future studies that include large enough samples to begin to disentangle the contribution of gender, age, and ethnicity in predicting disclosure.

Support for hypothesized ethnic differences in disclosure patterns was not found. An examination of the proportion of children who were aware of their mothers' serostatus highlights trends consistent with previous data (100\% of European American, 56\% of African American, and $55 \%$ of Latina mothers told their children). The extremely low number of European American participants $(N=3)$ effectively prevented any ethnic comparisons of this group. 
Mothers who were not married were more likely to have disclosed their serostatus to their children than were currently partnered mothers. As suggested by Armistead et al., 2001 in explaining higher rates of disclosure among mothers with lower incomes (Armistead et al., 2001), fewer resources may have made it more difficult to keep their illness hidden from children. Consistent with high rates of disclosure among widowed women found in a sample of AfricanAmerican HIV-infected mothers (Armistead et al., 2001), children who had lost a father to AIDS were more likely to be informed about their mother's illness than were children whose fathers were currently living. Unfortunately, systematic data regarding the timing of disclosure were not collected and, thus it is unclear whether disclosure preceded paternal death or whether the father's death provided an opportunity for disclosure. Regardless of whether the father's passing heightened children's curiosity and questions about maternal health status, led to increased chances of inadvertent disclosure occurring, or provided a suitable context in which the mother felt ready to disclose, higher rates of disclosure emphasize the need to understand disclosure processes among this subgroup of children who have already lost one parent to AIDS.

Consistent with expectations about the association between illness-related variables and disclosure, neither length of time since diagnosis, stage of illness, nor objective indicators of disease severity were related to disclosure. Somewhat unexpectedly and contrary to findings indicating that mothers reporting more health-related symptoms are more likely to disclose (Armistead et al., 2001), current results suggest higher rates of disclosure in families where children view their mother's illness as less severe and mothers are less upset by their illness. Although firm conclusions await longitudinal research with larger samples, possible explanations are suggestive. Given the large number of women receiving effective medication treatments, it 
may be that many wait to disclose until their health stabilizes and/or until they are less psychologically distressed about their diagnosis. Alternatively, disclosure may be associated with positive effects on maternal health and outlook (Petrie et al., 1998).

Consonant with results from several studies of the relationship between illness disclosure and child psychosocial adjustment (Armistead et al., 1997, 2001; Murphy et al., 2001; Murphy, Marelich et al., 2002), disclosure was not related to teacher, mother, or child reports of child functioning. As suggested by Armistead and colleagues (2001), the presence of potentially positive consequences of disclosure (e.g., lower maternal stress), as well as unsalutary effects (e.g., increased child stress) may balance each other out thereby explaining the null finding. Although disclosure was found to be associated with higher rates of child depressive symptoms and lower grade point average in a sample of children affected by paternal HIV infection and hemophilia, disclosure did not uniquely contribute to the prediction of child functioning once the effects of the parent-child relationship were included (Armistead et al., 1997). Studies which suggest that concurrent and later adolescent difficulties are associated with disclosure, unfortunately, failed to include measures of mother-child relationship and family functioning (Rotheram-Borus et al., 1997) or to examine the unique influence of independent family stress (Lee \& Rotheram-Borus, 2002). Thus, it is impossible to know whether differences in child age, diagnostic status, and/or gender of the ill parent or whether the failure to consider disclosure within the context of familial processes, account for the discrepant findings.

For issues surrounding secrecy, there was some disagreement between child and mother reports of whether diagnostic information was to be kept hidden from others. Children who reported that their mothers had requested secrecy were found to have more teacher-reported 
internalizing difficulties and lower levels of self-reported social competence. Thus, inhibition may not have come without emotional costs.

Relatedly, differential disclosure, which occurred in one-third of the families, was related to poorer child functioning in the form of higher overall levels of internalizing symptoms in the children. More of these children, compared with children from families in which disclosure status was consistent across all family members, evidenced psychological problems severe enough to warrant clinical attention. Consistent with studies suggesting that emotional secrecy is strongly associated with negative health and mental health outcomes among adults (Finkenauer and Rime, 1998a, 1998b), the current results highlight the need to understand more about the short- and long-term impact of secrecy on children whose mothers are seropositive. Given the tendency of individuals to ruminate and seek out opportunities to share emotionally meaningful events (Rime, 1999), it may be that children who are prevented, either implicitly or explicitly, from sharing news with close others are also denied the opportunity to relieve emotional inhibition, to cognitively understand the stressor, and to behaviorally and socially connect with others around the news.

Finally, in an attempt to empirically investigate differences between "knowing" and “naming" in families affected by maternal HIV (Nagler et al., 1995), discrepancies between child and mother reports of illness-related knowledge were explored. Children who reported knowing more about their mother's illness than what their mothers separately reported their children knew evidenced significantly higher rates of clinical levels of teacher-reported externalizing problems and mother-reported internalizing difficulties, as well as lower teacher ratings of behavioral competence than did children who reported knowing the same or less. Similarly, mothers who reported suspecting that their children knew more than what they themselves had disclosed, also 
reported higher levels of child externalizing and internalizing difficulties when compared with mothers who indicated their children only knew as much as they had been told by the mothers themselves. Although the number of participants involved in these analyses was too small to draw firm conclusions and the findings need to be replicated in larger samples, the results are consistent with the clinical experience reported by professionals working with these families. Coined the "nameless dread" (Nagler et al., 1995), maternal HIV/AIDS may become something "wrong" which is not named, explained, or discussed.

Unlike the inhibition associated with secrecy and differential disclosure, which appears to be primarily associated with difficulties of an internalizing nature, knowing more seems to be related to broader child difficulties. In each situation the potential for emotional and cognitive processing of the information seems thwarted. While it may be the case that children with behavioral and emotional difficulties are simply told less about their mother's illness, it may also be that frustration, hopelessness, and helplessness associated with perceptions of others as withholding information contribute to internalizing and externalizing problems. Although intriguing possibilities, results from the exploratory analyses of secrecy, differential disclosure, and knowledge discrepancy involved extremely small numbers of participants ( $N=4$ in one case). As such they are reported and discussed in the service of hypothesis generation for future research. Should such findings be replicated and extended longitudinally, they may prove useful in informing clinical interventions designed to assist families affected by maternal HIV infection.

Several limitations of the current study warrant attention. One was the inclusion of children from a wide range of developmental levels, which made it difficult to interpret the discrepancies among existing studies of the pervasiveness and nature of child maladjustment 
among HIV-affected families. A second limitation involved the cross-sectional, correlational, and descriptive nature of the research design that precludes any conclusions about directions of influence or causality. Third, a small sample size that limited statistical power and severely constrained the examination of complex multivariate relationships among several variables simultaneously was also a major drawback. Finally, the current research relied solely on selfreport data, and as such, the possibility that common method variance accounts for some of the results cannot be ruled out. Needed are large-scale, longitudinal studies that follow newly diagnosed or high-risk mothers and their children in order to examine adjustment and disclosure processes as they unfold and interact over time. Such investigations promise not only to enhance our understanding of the possible mechanisms through which HIV infection exerts its effects, but also to provide clarity regarding timing issues and the dismantling of packages of adversity confronting these families.

These limitations should be considered within the context of the study's numerous strengths. The study was one of the first to examine disclosure issues from the perspective of the noninfected child (see Murphy et al., 2006) and to explore family issues previously not examined (e.g., secrecy, differential disclosure). Both child competence and emotional/behavioral difficulties were assessed across multiple reporters, important in that each contribute to a fuller understanding of child functioning. Finally, this study adds to the scarce literature on parenting and child functioning within the context of HIV-infection, a timely issue given the growing rates of infection among women of childbearing age and the relative neglect of HIV-affected families.

Findings pertinent to disclosure processes offer important clinical information for professionals providing services to families affected by HIV. Although one can never prove the 
null hypothesis, there is an evolving consensus that no systematic relationships between disclosure and child adjustment have been found, implying, at the very least, that HIV-infected mothers should not be actively discouraged from telling their children about their condition (Murphy et al., 2006). It is possible to distill two caveats from what was learned about the varied timing and diverse ways in which disclosure occurred in these families. First, there is no one "right" way to tell or "right" age at which to disclose. Second, disclosure is a process, not a discrete event, and it is intricately linked with the larger family context in which it occurs (Lipson, 1994). Illustrating this concept, one mother's disclosure was the extension of a close and open relationship with family members, 'I've always told my kids everything, so it wasn't so much a decision as just part of the way things are. It was not a conscious decision to tell him, it was just natural to do so." This particular mother and adolescent continued to report having a close and positive postdisclosure relationship. Although they indicated that HIV was not a topic of daily discussion, communication about HIV, changes in health status, and feelings about diagnosis were ongoing. Information gleaned about emotional reactions and reasons for disclosure and nondisclosure may be useful in assisting mothers who are in various stages of the decision making process. For those who are considering telling their children about their diagnosis, several steps may be useful in preparing them for the process including: contemplating and preparing for all possible reactions; honestly considering what the child may already know; learning about the typical ways in which children cope with and process stressful situations (including developmental differences and the ways in which children continue to seek information as they mature and develop); thinking about the effects such news may have on the child and the relationship; practicing developmentally appropriate ways to impart the information; deciding 
how to handle issues around telling others; and developing and implementing a plan to keep the topic open for discussion over time.

If the current findings should survive replication, professionals may want to inform mothers about the possible burden of secrecy so that the complex advantages and disadvantages of swearing a child to secrecy; of disclosing to some, but not all, family members; and of not being fully honest about what the child "knows" and sees can be openly considered. For example, if children are of drastically different ages, it may be difficult, if not impossible, to withhold disclosure from an older child before informing a younger sibling. However, considering the strain that secrets can place on family openness and communication, as well as on the individual child who must withhold information from a younger sibling, a mother who has carefully considered such factors may make different decisions. She may decide to tell the younger child sooner than if s/he was an only child and/or she may discuss the situation with the older child in order to explain the reason for differential disclosure. Similarly, a mother who honestly acknowledges that a child already knows that "something" is wrong may feel empowered to open up the lines of communication after considering some of the possible disadvantages associated with continued withholding of information (e.g., maternal guilt over concealment; avoidance of closeness with the child to prevent questions; child confusion, mistrust, anger).

Although the current study yields useful information about the disclosure process and possible outcomes, our understanding and knowledge of the complex experiences affecting the lives of families coping with maternal HIV infection remains woefully incomplete. Needed are collaborative efforts that allow for the recruitment of large and representative samples that will allow for the examination of multiple influences on the disclosure process over time. 


\section{Acknowledgments}

This research was supported in part by a seed grant from the Universitywide AIDS Foundation. This research was part of the author's doctoral dissertation and a portion of the current study was previously presented at the 2003 meeting of the Society for Research in Child Development in April, 2003. I gratefully acknowledge Gail Wyatt for offering collaborative opportunities. I thank Barbara Henker for her support and mentorship. I thank Marisabel Canedo, Tasha Emmerson, Mercedes Floresislas, Tanya Hilty, Jamie Manwaring, Jaime Paz, Nuri Reyes, and Jenna Shih for their assistance with data collection, entry, and coding. I extend my deepest appreciation to the women and children who so openly shared about their experiences with HIV infection. 


\section{References}

Achenbach, T. M. (1991a). Manual for the Child Behavior Checklist 4-18 and 1991 profile. Burlington, VT: University of Vermont Department of Psychiatry.

Achenbach, T. M. (1991b). Manual for the Youth Self-Report and 1991 profile. Burlington, VT: University of Vermont Department of Psychiatry.

Achenbach, T. M., \& Edelbrock, C. S. (1986). Manual for the Teacher Report Form of the child behavior profile. Burlington, VT: University of Vermont Department of Psychiatry.

Antle, B. J., Wells, L. M., Goldie, R. S., DeMatteo, D., \& King, S. M. (2001). Challenges of parenting for families living with HIV/AIDS. Social Work, 46, 159-169.

Armistead, L., \& Forehand, R. (1995). For whom the bell tolls: Parenting decisions and challenges faced by mothers who are HIV seropositive. Clinical Psychology: Science and Practice, 2, 239-250.

Armistead, L., Klein, K., Forehand, R., \& Wierson, M. (1997). Disclosure of parental HIV infection to children in the families of men with hemophilia: Description, outcomes, and the role of family processes. Journal of Family Psychology 11, 49-61.

Armistead, L., Summers, P., Forehand, R., Morse, P. S., Morse, E., \& Clark, L. (1999). Understanding of HIV/AIDS among children of HIV-infected mothers: Implications for prevention, disclosure, and bereavement. Children's Health Care, 28, 277-295.

Armistead, L., Tannenbaum, L., Forehand, R., Morse, E., \& Morse, P. (2001). Disclosing HIV status: Are mothers telling their children? Journal of Pediatric Psychology, 26, 11-20.

Bauman, L. J., Camacho, S., Silver, E. J., Hudis, J., \& Draimin, B. (2002). Behavioral problems in school-aged children of mothers with HIV/AIDS. Clinical Child Psychology 
and Psychiatry, 7, 39-54.

Centers for Disease Control and Prevention (2002). HIV/AIDS surveillance report, 14, 1-48. Atlanta, GA: Author.

Dorsey, S., Chance, M. W., Forehand, R., Morse, E., \& Morse, P. (1999). Children whose mothers are HIV infected: Who resides in the home and is there a relationship to child psychosocial adjustment? Journal of Family Psychology, 13, 103-117.

Edelbrock, C. S., \& Achenbach, T. M. (1984). The teacher version of the child behavior profile: Boys age 6-11. Journal of Consulting and Clinical Psychology, 52, 207-217.

Esposito, S., Musetti, L., Musetti, M. C., Corbella, S., Massironi, E., Marchisio, P., et al. (1999). Behavioral and psychological disorders in uninfected children aged 6 to 11 years born to Human Immunodeficiency Virus-seropositive mothers. Developmental and Behavioral Pediatrics, 20, 411-417.

Faithfull, J. (1997). HIV-positive and AIDS-infected women: Challenges and difficulties of mothering. American Journal of Orthopsychiatry, 67, 144-151.

Finkenauer, C., \& Rime, B. (1998a) Socially shared emotional experiences vs. emotional experiences kept secret: Differential characteristics and consequences. Journal of Social and Clinical Psychology, 17, 295-318.

Finkenauer, C., \& Rime, B. (1998b). Keeping emotional memories secret: Health and subjective well-being when emotions are not shared. Journal of Health Psychology, 3, 4758.

Forsyth, B.W. C., Damour, L., Nagler, S., \& Adnopoz, J. (1996). The psychological effects of parental human immunodeficiency virus infection on uninfected children. Archives of 
Pediatric Adolescent Medicine, 150, 1015-1020.

Grant, K. E., \& Compas, B. E. (1995). Stress and anxious-depressed symptoms of anxiety/depression among adolescents: Searching for mechanisms of risk. Journal of Consulting and Clinical Psychology, 63, 1015-1021.

Harter, S. (1985). Manual for the Self-Perception Profile for Children. Denver, CO: University of Denver.

Jamison, R. N., \& Walker, L. S. (1992). Illness behavior in children of chronic pain patients. International Journal of Psychiatry in Medicine, 22, 329-342.

Joint United Nations Programme on HIV/AIDS. (2000). Report on the Global HIV/AIDS Epidemic. Geneva, Switzerland: Author.

Lee, M. L., \& Rotheram-Borus, M. J. (2002). Parents' disclosure of HIV to their children. AIDS, 16, 2201-2207.

Lester, P., Chesney, M., Cooke, M., Whalley, P., Perez, B., Petru, A., et al. (2002). Diagnostic disclosure to HIV-Infected children: How parents decide when and what to tell. Clinical Child Psychology and Psychiatry, 7, 85-99.

Lipson, M. (1994). Disclosure of diagnosis to children with Human Immunodeficiency Virus or Acquired Immunodeficiency Syndrome. Developmental and Behavioral Pediatrics, 15, S61-S65.

Melvin, D. (1996). “Don't forget the children”: Families living with HIV infection. In L. Sherr, C. Hankins \& L. Bennett (Eds.), AIDS as a gender issue: Psychosocial perspectives (pp. 215-234). London: Taylor and Francis, Ltd.

Moneyham, L., Seals, B., Demi, A., Sowell, R., Cohen, L., \& Guillory, J. (1996). Experiences 
of disclosure in women infected with HIV. Health Care for Women International, 17, 209-221.

Murphy, D. A., Dello Stritto, M. E., \& Steers, W. N. (2001). Maternal disclosure of mothers' HIV serostatus to their young children. Journal of Family Psychology, 15, 441-450.

Murphy, D. A., Marelich, W. D., \& Hoffman, D. (2002). A longitudinal study of the impact on young children of maternal HIV serostatus disclosure. Clinical Child Psychology and Psychiatry, 7, 55-70.

Murphy, D. A., Roberts, K. J., \& Hoffman, D. (2002). Stigma and ostracism associated with HIV/AIDS: Children carrying the secret of their mothers' HIV+ serostatus. Journal of Child and Family Studies, 11, 191-202.

Murphy, D. A., Roberts, K. J., \& Hoffman, D. (2003). Regrets and advice from mothers show have disclosed their HIV+ serostatus to their young children. Journal of Child and Family Studies, 12, 307-318.

Murphy, D. A., Roberts, K. J., \& Hoffman, D. (2006). Young children's reactions to mothers' disclosure of HIV+ serostatus. Journal of Child and Family Studies, 15, 307-318.

Nagler, S. F., Adnopoz, J., \& Forsyth, B. W. C. (1995). Uncertainty, stigma, and secrecy. Psychological aspects of AIDS for children and adolescents. In S. Geballe, J. Gruendel, \& W. Andiman (Eds.), Forgotten children of the AIDS epidemic (pp. 71-82). New Haven, CT: Yale University Press.

Niebuhr, V. N., Hughes, J. R., \& Pollard, R. B. (1994). Parents with Human Immunodeficiency Virus infection: Perceptions of their children's emotional needs. Pediatrics, 93, 421-426. Nostlinger, C., Jonckheer, T., de Belder, E., van Wijngaerden, E., Wylock, C., Pelgrom, J. et al. 
(2004). Families affected by HIV: Parents' and children's characteristics and disclosure to the children. AIDS Care, 16, 641-648.

Ostrom, R. A., Serovich, J. M., Lim, J. Y., \& Mason, T. L. (2006). The role of stigma in reasons for HIV disclosure and non-disclosure to children. AIDS Care, 18, 60-65.

Petrie, K. J., Booth, R. J., \& Pennebaker, J. W. (1998). The immunological effects of thought suppression. Journal of Personality and Social Psychology, 75, 1264-1272.

Pilowsky, D. J., Sohler, N., \& Susser, E. (1999). The parent disclosure interview. AIDS Care, $11,447-452$.

Radloff, L. S. (1977). The CES-D scale: A self-report depression scale for research in the general population. Applied Psychological Measurement, 1, 385-401.

Rime, B. (1999). Expressing emotion, physical health, and emotional relief: A cognitive-social perspective. Advances in Mind-Body Medicine, 15, 161-195.

Rotheram-Borus, M. J., Dramin, B. H., Reid, H. M., \& Murphy, D. A. (1997). The impact of illness disclosure and custody plans on adolescents whose parents live with AIDS. AIDS, $11,1159-1164$.

Schrimshaw, E. W., \& Siegel, K. (2002). HIV-infected mothers' disclosure to their uninfected children: Rates, reasons, and reactions. Journal of Social and Personal Relationships, 19, 19-43.

Shaffer, A., Jones, D. J., Kotchick, B. A., Forehand, R., \& The Family Health Project Research Group. (2001). Telling the children: Disclosure of maternal HIV infection and its effects on child psychosocial adjustment. Journal of Child and Family Studies, 10, 301-313.

Simoni, J. M., Mason, H. R. C., Marks, G., Ruiz, M. S., Reed, D., \& Richardson, J. L. (1995). 
Women's self-disclosure of HIV infection: Rates, reasons, and reactions. Journal of Consulting and Clinical Psychology, 63, 474-478.

Sowell, R. L., Seals, B. F., Moneyham, L., Demi, A., Cohen, L., \& Brake, S. (1997). Quality of life in HIV-infected women in the south-eastern United States. AIDS Care, 9, 501-512.

Tompkins, T. L., Henker, B., Whalen, C. K., Axelrod, J., \& Comer, L. K. (1999). Motherhood in the context of HIV infection: Reading between the numbers. Cultural Diversity and Ethnic Minority Psychology, 5, 197-208.

Ware, J., \& Sherbourne, C. D. (1992). The MOS 36-item short-form health survey (SF-36). Medical Care, 30, 473-483.

Wiener, L. S., Battles, H. B., \& Heilman, N. E. (1998). Factors associated with parents' decision to disclose their HIV diagnosis to their children. Child Welfare, 77, 115-135.

Wyatt, G. E., \& Chin, D. (1999). HIV and ethnic minority women, families, and communities: An overview. Cultural Diversity and Ethnic Minority Psychology, 5, 179-182. 
Table I: Mean Maternal-and Child-Reported Initial and Current Child Responses to Disclosure

\begin{tabular}{|c|c|c|c|c|}
\hline \multirow[b]{2}{*}{ Response } & \multicolumn{2}{|c|}{ Maternal Report } & \multicolumn{2}{|c|}{ Child Report } \\
\hline & Initial & Current & Initial & Current \\
\hline Worry $^{\mathrm{a}}$ & $1.79(1.31)$ & $.71(0.99)^{*}$ & $2.14(1.03)$ & $1.57(1.09)$ \\
\hline Sadness & $1.85(1.21)$ & $.85(1.07)$ & $1.93(1.21)$ & $1.14(1.03)^{*}$ \\
\hline Confusion & $1.71(0.91)$ & $.36(0.63)^{* *}$ & $1.64(1.22)$ & $.14(0.36)^{* *}$ \\
\hline Shock & $1.46(1.33)$ & $.38(0.87)$ & $2.00(1.11)$ & $.43(0.94) * *$ \\
\hline Anger & $.93(1.07)$ & $.64(0.93)$ & $.86(1.17)$ & $.57(0.85)$ \\
\hline Stress & $1.29(1.27)$ & $.64(0.93)$ & $1.14(1.29)$ & $.64(0.93)$ \\
\hline Relief & $.69(1.03)$ & $1.15(1.07)$ & $.64(0.93)$ & $.86(1.23)$ \\
\hline Hope & $1.43(1.16)$ & $2.14(1.29)^{*}$ & $2.00(1.11)$ & $2.14(1.17)$ \\
\hline \multicolumn{5}{|c|}{ Note. Values enclosed in parentheses represent standard deviations. The higher the rating } \\
\hline${ }^{\mathrm{a}}$ Children $\mathrm{r}$ & ted higher & of current wc & nothers. & \\
\hline
\end{tabular}

